\title{
Ambientes para a produção de mudas e nodulação por rizóbios em Tachigali vulgaris
}

\author{
Environments for seedling production and nodulation by rhizobia in Tachigali vulgaris \\ Juciane Casaes de Souza ${ }^{\mathrm{I}}$, Cássia Ângela Pedrozo ${ }^{\mathrm{II}}$, Krisle da Silva ${ }^{\mathrm{III}}$, \\ Vanúbia Ximendes Aragão Oliveira ${ }^{\mathrm{IV}}$, Andressa Maria da Silva Alencar ${ }^{\mathrm{IV}}$
}

\begin{abstract}
Resumo
O presente estudo teve como objetivos determinar a melhor condição de sombreamento e o tipo de substrato para a produção de mudas e estabelecimento da simbiose espontânea por rizóbios em taxi-branco (Tachigali vulgaris). O experimento foi instalado no delineamento de blocos casualizados, com quatro repetições e os tratamentos arranjados em esquema de parcela subdividida, no qual a parcela consistiu de dois níveis de sombreamento $(50 \%$ e $75 \%$ ) e a subparcela de quatro tipos de substrato: solo; solo + areia (1:1); solo + areia + serragem (2:1:1); e solo + vermiculita (1:1). Cada parcela experimental foi constituída por cinco mudas. As mudas foram avaliadas quanto a um conjunto de variáveis morfológicas e fisiológicas, da parte aérea e da raiz. No final do experimento foi também realizado o isolamento e a caracterização fenotípica de bactérias oriundas de nódulos coletados nas mudas. A caracterização foi realizada pela avaliação morfológica das colônias. O sombreamento de $50 \%$ é o indicado na produção de mudas de taxi-branco, enquanto que, em relação ao substrato, aquele composto por solo + areia é o que proporciona mudas de melhor qualidade. A espécie apresentou simbiose com grande diversidade de rizóbios, apesar de o número de isolados não ter sido influenciado pelo tipo de substrato e nível de sombreamento. A maioria dos isolados obtidos apresentam tempo de crescimento muito rápido e $\mathrm{pH}$ ácido do meio de cultura.
\end{abstract}

Palavras-chave: Taxi-Branco; Viveiro; Fixação biológica de nitrogênio

\begin{abstract}
This study had as objectives to determine the best shading condition and the type of substrate to produce seedlings and the establishment of a spontaneous symbiosis by rhizobia in taxi-branco (Tachigali vulgaris). A randomized block design with four replications and treatments arranged in a split-plot scheme was installed. The plot consisted of two shading levels (50\% and 75\%) and subplots of four types of substrates: soil; soil + sand (1:1); soil + sand + sawdust (2:1:1); and soil + vermiculite (1:1). Each experimental plot consisted of five seedlings. The seedlings were evaluated for a set of shoot and root morphological and physiological traits. At the end of the experiment, the isolation and the phenotypic characterization of bacteria from nodules collected in the seedlings were also carried out. The characterization was performed by the morphological evaluation of the colonies. The shading of $50 \%$ is indicated for seedling productions, while in relation to the substrate, that one composed by soil + sand is what produces seedlings of better quality. Although the number of isolates was not influenced by the substrate type and the shading level, taxibranco seedlings establish symbiosis with a great diversity of rhizobia. Most of the isolates have very fast growth rate and acid $\mathrm{pH}$ of the culture medium.
\end{abstract}

Keywords: Taxi-branco; Nursery; Biological fixation of nitrogen

\footnotetext{
I Tecnóloga em Gestão Ambiental, MSc., Agroecologia, Universidade Estadual de Roraima, Rua 7 de setembro, 231, Canarinho, CEP 69306-530, Boa Vista (RR), Brasil. jucianecasaes@hotmail.com (ORCID: 0000-0001-7300-4430)

${ }^{\text {II }}$ Engenheira Agrônoma, Dra ${ }^{\text {. }}$, Pesquisadora da Embrapa Roraima, Rodovia BR 174, Km 174, Distrito Industrial, CEP 69301-970, Boa Vista (RR), Brasil. cassia.pedrozo@embrapa.br (ORCID: 0000-0002-0474-263X)

III Engenheira Agrônoma, Dr ${ }^{\mathrm{a}}$., Pesquisadora da Embrapa Florestas, Estrada da Ribeira, Km 111, Parque Monte Castelo, CEP 83411-000, Colombo (PR), Brasil. krisle.silva@embrapa.br (ORCID: 0000-0002-2512-9519)

Iv Bióloga, Faculdades Cathedral, Av. Luís Canuto Chaves, 293, Caçari, CEP 69307-053, Boa Vista (RR), Brasil. vanubia.ximendes@hotmail.com (ORCID: 0000-0002-4698-9286) / andressa.silvaalencar@hotmail.com (ORCID: 0000-0003-0808-5224)
} 


\section{Introdução}

Com o aumento dos plantios florestais nos últimos anos, aumentou, também, a importância da produção de mudas de espécies arbóreas nativas (DUTRA, 2010), sendo necessários estudos para garantir a qualidade das mudas formadas e, consequentemente, para aumentar as chances de sucesso no plantio. Tachigali vulgaris L.G. Silva e H.C. Lima (taxi-branco) é uma espécie de porte médio, pertencente à família Fabaceae e que apresenta ocorrência natural em áreas de terra firme. Ocorre em quase todo o território brasileiro, com exceção da região sul (LORENZI, 2002; LIMA, 2004).

O taxi-branco possui grande potencial para reflorestamentos (FREITAS et al., 2012), uma vez que apresenta ocorrência em áreas com distintas características edafoclimáticas, possui rápido crescimento e, consequentemente, grande produção de biomassa. Sua madeira apresenta boas características para a produção de carvão vegetal e lenha (DIAS et al., 1992; LORENZI, 2002; VALE et al., 2002). Estabelece simbiose com bactérias fixadoras de nitrogênio, denominadas de rizóbios (CALDEIRA et al., 1999), podendo este fator ser importante na redução da mortalidade das mudas na fase de viveiro (MARINHO et al., 2004).

A avaliação da qualidade de mudas florestais em viveiro se relaciona diretamente com variáveis morfológicas e fisiológicas, dependendo da escolha feita em relação ao recipiente, substrato e sombreamento, das técnicas de produção e manejo e do tempo gasto no viveiro (GOMES, 2001). Dentre estes, o tipo de substrato e o nível de sombreamento merecem destaque, devendo-se levar em consideração a exigência e tolerância de cada espécie (DUTRA, 2010). Estudos com espécies nativas têm demonstrado exigências diferenciadas em relação ao nível de sombreamento (ALMEIDA et al., 2005; AGUIAR et al., 2011; GONÇALVES et al., 2012; CONCEIÇÃO; DIAS-FILHO, 2013; LENHARD et al., 2013; PACHE$\mathrm{CO}$ et al., 2013), dependendo do grupo ecológico que a espécie pertence. Em relação ao substrato, dentre outros, aqueles compostos por solo, areia, esterco, vermiculita, serragem e casca de arroz (CARVALHO FILHO et al., 2003; CUNHA et al., 2005; DANTAS et al., 2009; DUTRA; MASSAD; SANTANA, 2012), combinados em diversas proporções, têm sido os utilizados. Substratos compostos por resíduos orgânicos e disponíveis na região de interesse devem ser priorizados visando reduzir o custo de produção e aumentar a qualidade das mudas.

Estudos isolados, relacionados ao sombreamento e ao substrato, demonstraram que mudas de taxi-branco se desenvolvem melhor sob maiores condições de luminosidade (FELFILI et al., 1999; FREITAS et al., 2012) e com uso de substrato composto por mistura de solo argiloso, areia e matéria orgânica curtida, na proporção de 3:1:1 (SOUZA et al., 2004). Em relação à nodulação, Felfili et al. (1999) e Souza et al. (2004) observaram nodulação em raízes da espécie, embora não tenha sido avaliada a influência da nodulação na qualidade das mudas. Estudos considerando, conjuntamente, o sombreamento, o substrato e a simbiose com bactérias fixadoras de nitrogênio são importantes, pois podem favorecer o desenvolvimento de mudas de melhor qualidade de crescimento e, consequentemente, plantios com mudas mais vigorosas e resistentes. Sendo assim, o presente estudo teve como objetivos determinar a melhor condição de sombreamento e tipo de substrato para o crescimento e nodulação em mudas de taxi-branco.

\section{Material e método}

\section{Análises de variáveis morfológicas e fisiológicas}

O estudo foi conduzido no viveiro e no Laboratório de Microbiologia do Solo da Embrapa Rorai-

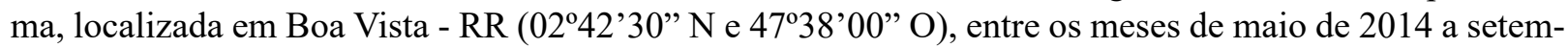
bro de 2015. Foi utilizada mistura de sementes de 28 árvores-matrizes provenientes de três procedências (Belterra - PA, Laranjal do Jari - AP e Santarém - PA) para produção das mudas. O delineamento experimental utilizado foi o de blocos casualizados, com quatro repetições, sendo os tratamentos arranjados em esquema de parcela subdividida. As parcelas consistiram de dois níveis de sombreamento $(50 \%$ e $75 \%)$ e as subparcelas de quatro tipos de substrato (solo - S1; solo + areia na proporção volumétrica de 1:1 - S2; solo + areia + serragem na proporção de 2:1:1 - S3; e solo + vermiculita na proporção de 1:1 - S4). 
Mensalmente, até os seis meses após o transplantio, as mudas foram avaliadas quanto à altura $($ ALT; $\mathrm{cm})$ e do quarto ao sexto mês quanto ao diâmetro do coleto (DC; $\mathrm{mm}$ ). Na avaliação final, realizada seis meses após o transplantio, além das variáveis descritas anteriormente, a porcentagem de mortalidade $(\mathrm{M} ; \%)$, índice de clorofila total $\left(\mathrm{Chl}_{\text {total }}\right)$, razão entre os índices de clorofila $a$ e $b\left(\mathrm{Chl}_{a} / \mathrm{Chl}_{b}\right)$, área foliar $\left(\mathrm{AF} ; \mathrm{cm}^{2}\right.$ ), massa seca da parte aérea (MSPA; g), massa seca da raiz (MSR; g), massa seca total (MST, g), razão entre MSPA e MSR (PA/R), índice de qualidade de Dickson (IQD) e número de nódulos na raiz (NN) também foram avaliados.

Os índices de $\mathrm{Chl}_{a}$ e $\mathrm{Chl}_{b}$ foram obtidos pela média de três medições realizadas nos três últimos folíolos, contando do ápice para a base da folha, da terceira folha completamente expandida, contando do ápice para a base do caule. Os dados foram coletados utilizando o clorofilômetro digital CLOROFILOG-CFL1030. Estes índices foram utilizados para calcular as variáveis $\mathrm{Chl}_{\text {total }}$ e Chl $/ \mathrm{Chl}_{b}$. A AF foi avaliada utilizando o medidor de área foliar LI-3100C. Para obtenção da MSPA e MSR, a parte aérea e a raiz foram acondicionadas, individualmente, em sacos de papel e levadas à estufa de circulação de ar forçada a 60 ${ }^{\circ} \mathrm{C}$, até atingirem peso constante, sendo posteriormente pesadas em balança de precisão de $0,01 \mathrm{~g}$. Para determinação do $\mathrm{NN}$, os nódulos foram destacados das raízes ainda frescos, sendo realizada a contagem destes em cada muda avaliada.

Os dados obtidos foram inicialmente submetidos ao teste de homogeneidade de Cochran e ao teste de normalidade de Shapiro-Wilk. As variáveis NN, MSR e IQD tiveram os dados transformados para . Posteriormente, foi realizada análise de variância, sendo as médias comparadas pelo teste de Tukey, em nível de $5 \%$ de probabilidade. No caso das variáveis ALT e DC, as quais foram avaliadas ao longo do tempo, os dados foram estudados por análise de regressão. O Programa Sisvar 5.3 foi utilizado nas análises estatísticas (FERREIRA, 2011).

\section{Análises microbiológicas}

Para o isolamento das bactérias foram utilizados 304 nódulos, sendo dois de cada muda sobrevivente e que apresentou nódulos (152). Após a coleta, foi realizada a reidratação dos nódulos em água destilada estéril por 16 horas e a quebra da tensão superficial com imersão em álcool etílico $96 \%$ por 30 segundos. Posteriormente, foi feita a desinfestação da superfície dos nódulos com imersão em solução de hipoclorito de sódio $5 \%$ por 5 minutos, seguido por seis lavagens com água destilada estéril. Por fim, os nódulos foram individualmente macerados e espalhados sobre meio de cultura 79 (FRED; WASKMAN, 1928) com adição de vermelho congo $0,25 \%$ e incubados à $28^{\circ} \mathrm{C}$ por até 15 dias. Após o aparecimento de colônias, as bactérias foram repicadas sobre meio de cultura YMA com azul de bromotimol 0,5\%, até a purificação das mesmas. O número de isolados (NI) foi contabilizado.

A caracterização fenotípica dos isolados foi realizada através da caracterização morfológica das colônias. Para isto, três colônias isoladas de cada placa foram avaliadas quanto ao tamanho inicial e final $(\mathrm{mm})$, tempo de crescimento (horas), forma da colônia, borda, elevação, superfície da colônia, produção de muco, elasticidade, transparência do muco, coloração, aparência do muco, consistência e pH do meio.

Os dados obtidos da caracterização dos isolados foram transformados em código binário, sendo 0 para ausência e 1 para presença, sendo a similaridade calculada pelo coeficiente de Jaccard. A matriz de similaridade gerada foi utilizada para análise de agrupamento pelo método da Ligação Média Entre Grupos. O programa NTSYS-pc, versão 2.1, foi utilizado. Os dados do NI foram transformados para e submetidos às mesmas análises estatísticas realizadas para as variáveis morfológicas e fisiológicas avaliadas aos seis meses após o transplantio.

\section{Resultados e discussão}

\section{Análises de variáveis morfológicas e fisiológicas}

Seis meses após o transplantio, as mudas de taxi-branco apresentaram mortalidade de $2,5 \%$, sendo metade na combinação $50 \%$ de sombreamento e substrato S3 e a outra metade igualmente distribuída entre 
as combinações de $75 \%$ de sombreamento e S2 e 75\% de sombreamento e S4. As variáveis altura (ALT) e diâmetro do coleto (DC) foram avaliadas ao longo do tempo, sendo observado para a primeira variável efeito significativo $(\mathrm{P}<0,05)$ para todos os fatores simples e interações, enquanto para a segunda, só não foi detectado efeito significativo para a interação tempo x substrato x sombreamento (T x SUB x SOM). Em relação às variáveis que foram avaliadas apenas no final do experimento, para o número de nódulos na raíz $(\mathrm{NN})$ foram observadas diferenças significativas entre as médias apenas para o fator substrato e para a interação sombreamento x substrato (SOM x SUB, enquanto para área foliar (AF), índice de clorofila total (Chl $\mathrm{Ctal}_{\text {) }}$, massa seca da raiz (MSR), massa seca da parte aérea (MSPA), massa seca total (MST), razão entre MSPA e MSR (PA/R) e índice de qualidade de Dickson (IQD), houve diferenças significativas tanto para os fatores simples, quanto para a interação (dados não apresentados). Finalmente, para a razão entre os índices de clorofila $a$ e $b\left(\mathrm{Chl}_{\mathrm{a}} / \mathrm{Chl}_{\mathrm{b}}\right)$ não foram observadas diferenças significativas para nenhum dos fatores simples e interação.

Figura 1 - Altura de mudas (ALT) de taxi-branco avaliadas em dois níveis de sombreamento, quatro tipos de substratos e seis épocas de avaliação $\left[\mathrm{S1} 1-50 \%: \mathrm{y}=\mathbf{2 , 8 8 0 6 x}+\mathbf{0 , 2 2 8}\right.$ e $\mathrm{R}^{2}=\mathbf{0 , 9 7 3 4}$; S1-75\%: $\mathbf{y}=3,8823 x-0,4713$ e R $R^{2}=0,9947 ; S 2-50 \%: y=2,488 x-0,0013$ e $R^{2}=0,9708 ; S 2-75 \%: y=2,9986 x$ $+0,7233$ e $R^{2}=0,9984 ;$ S3-50\%: $y=1,2851 x+1,022$ e $R^{2}=0,9528 ; S 3-75 \%: y=1,8377 x+0,598$ e $R^{2}$ $=0,9352 ; \mathrm{S} 4-50 \%: y=1,828 x+1,2287$ e $R^{2}=0,9943 ; S 4-75 \%: y=3,0586 x+0,5033$ e $R^{2}=0,9968$

(A); diâmetro do coleto de mudas (DC) avaliadas em dois níveis de sombreamento [50\%: y $=0,57 \mathbf{x}+$ 1,42 e $R^{2}=0,9854 ; 75 \%: y=0,22 x+1,55 \mathrm{e}^{2}=0,8501$ (B); e diâmetro de mudas (DC) avaliadas em quatro tipos de substratos $\left[S 1: y=0,515 x+1,69\right.$ e $R^{2}=0,9707 ; S 2: y=0,435 x+1,67$ e $R^{2}=0,9542 ; S^{3}$ : $y=0,365 x+1,61$ e $R^{2}=0,9433 ; S 4: y=0,26 x+0,99$ e $\left.R^{2}=0,9764\right]$ (C).

Figure 1 - Height of taxi-branco seedlings (ALT) evaluated at two levels of shading, four types of substrates and six evaluation times [S1-50\%: $\mathrm{y}=2,8806 \mathrm{x}+0,228$ and $\mathrm{R}^{2}=0,9734 ; \mathrm{S} 1-75 \%: \mathrm{y}=3,8823 \mathrm{x}$ $-0,4713$ and $R^{2}=0,9947 ; S 2-50 \%: y=2,488 x-0,0013$ and $R^{2}=0,9708 ; S 2-75 \%: y=2,9986 x+0,7233$ and $\mathrm{R}^{2}=0,9984 ; \mathrm{S} 3-50 \%: \mathrm{y}=1,2851 \mathrm{x}+1,022$ and $\mathrm{R}^{2}=0,9528 ; \mathrm{S} 3-75 \%: \mathrm{y}=1,8377 \mathrm{x}+0,598$ and $\mathrm{R}^{2}=$ 0,$9352 ; \mathrm{S} 4-50 \%: \mathrm{y}=1,828 \mathrm{x}+1,2287$ and $\mathrm{R}^{2}=0,9943 ; \mathrm{S} 4-75 \%: \mathrm{y}=3,0586 \mathrm{x}+0,5033$ and $\left.\mathrm{R}^{2}=0,9968\right]$

(A); stem diameter of seedlings (DC) evaluated at two levels of shade $\left[50 \%: \mathrm{y}=0,57 \mathrm{x}+1,42\right.$ and $\mathrm{R}^{2}=$ 0,9854; 75\%: $\mathrm{y}=0,22 \mathrm{x}+1,55$ and $\left.\mathrm{R}^{2}=0,8501\right](\mathrm{B})$; and stem diameter of seedlings (DC) evaluated on four types of substrates $\left[\mathrm{S} 1: \mathrm{y}=0,515 \mathrm{x}+1,69\right.$ and $\mathrm{R}^{2}=0,9707 ; \mathrm{S} 2: \mathrm{y}=0,435 \mathrm{x}+1,67$ and $\mathrm{R}^{2}=0,9542 ; \mathrm{S}^{3}$ : $\mathrm{y}=0,365 \mathrm{x}+1,61$ and $\mathrm{R}^{2}=0,9433 ; \mathrm{S} 4: \mathrm{y}=0,26 \mathrm{x}+0,99$ and $\left.\mathrm{R}^{2}=0,9764\right](\mathrm{C})$.

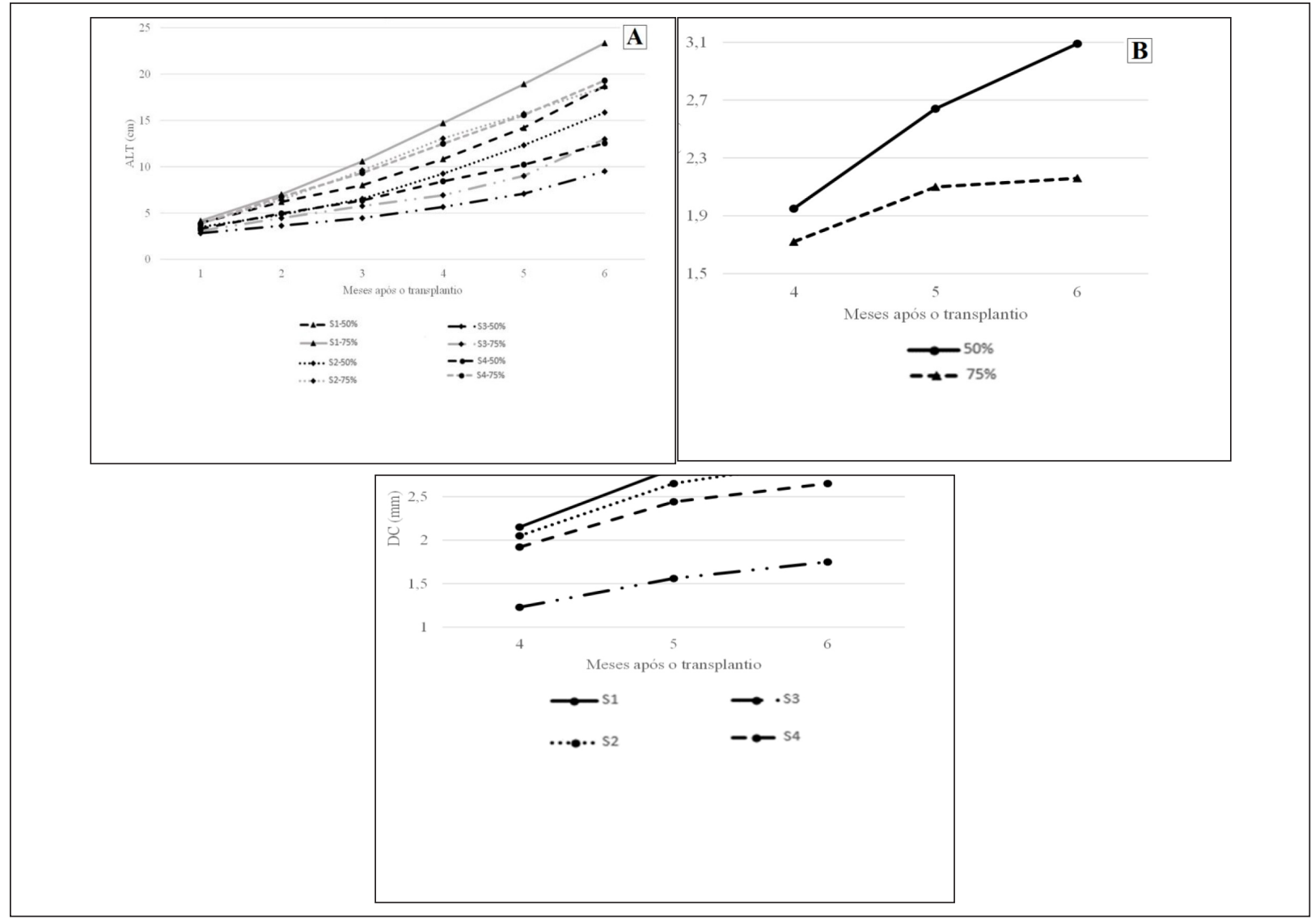


A altura se destaca como a melhor variável para avaliar o desenvolvimento das plantas em testes de sombreamento, uma vez que o rápido crescimento está relacionado com a adaptação ao tipo de ambiente (MORAES NETO et al., 2000). Foi observada resposta linear crescente e significativa para ALT ao longo das épocas de avaliação (Figura A), para todos os níveis de sombreamento e tipos de substrato testados, com as maiores médias observadas aos seis meses.

Até o segundo mês após o transplantio não foram observadas diferenças significativas para a ALT entre os níveis de sombreamento. No entanto, a partir do terceiro mês, as mudas cultivadas sob $75 \%$ de sombreamento, no geral, apresentaram maior crescimento, comparado ao nível de 50\%. Segundo Moraes Neto et al. (2000), essa resposta seria um mecanismo de adaptação encontrado em plantas, como estratégia de escape ao sombreamento.

Os resultados obtidos para a ALT sob maior nível de sombreamento são concordantes com aqueles obtidos por Felfili et al. (1999), ao avaliar mudas de Sclerolobium paniculatum var. rubiginosum (Tul.) Benth. Estes autores observaram que plantas cultivadas sob $90 \%$ de sombreamento tenderam a apresentar maiores valores de ALT, quando comparadas aos tratamentos de pleno sol, $50 \%$ de sombra e $70 \%$ de sombra. Freitas et al. (2012), ao avaliar mudas de taxi-branco em três condições de sombreamento $(50 \%$, pleno sol e sombra natural), encontraram maior crescimento de plantas no ambiente de 50\% de luminosidade comparado ao ambiente de pleno sol, com maior destaque a partir dos 103 dias de avaliação. Neste estudo, sob condição de sombra natural as plantas apresentaram maior altura inicial até os 93 dias. Em Belém, o taxi-branco desenvolveu-se bem tanto no sombreamento de $50 \%$ quanto no de $75 \%$, comparadas às mudas cultivadas sob sombreamento de 25\% (CONCEIÇÃO; DIAS-FILHO, 2013).

Em relação ao fator substrato, não foram observadas diferenças estatísticas significativas para a ALT no primeiro mês de avaliação. Contudo, a partir dos dois meses, considerando cada nível de sombreamento isoladamente, o substrato $\mathrm{S} 1$ foi o que mais se destacou nos dois níveis.

O diâmetro do coleto (DC) é uma variável importante na avaliação do potencial da muda para sobrevivência e crescimento após o plantio (SCALON et al., 2001), pois plantas com maior DC apresentam maior tendência à sobrevivência em campo (SIEBENEICHLER et al., 2008). As mudas que foram submetidas ao sombreamento de 50\% apresentaram maiores médias de DC em todos os meses de avaliação (Figura B). Segundo Felfili et al. (1999), os maiores valores de DC, obtidos por estes autores, para mudas de taxi-branco sob $50 \%$ de sombreamento, seguido de condição de pleno sol, são característicos de espécies heliófilas de fases iniciais de sucessão, o que permite a recomendação da espécie, em conjunto com espécies pioneiras de rápido crescimento, nas fases iniciais de recuperação de matas degradadas.

O nível de 50\% de sombreamento proporcionou os maiores valores de DC para todos os substratos, havendo destaque dos substratos S1 e S2 (Tabela 1). Os resultados quanto ao sombreamento concordam parcialmente com aqueles obtidos por Freitas et al. (2012), em que plantas de taxi-branco, avaliadas sob sombreamento natural, apresentaram menores taxas de crescimento do colo, em comparação às plantas submetidas a pleno sol. Neste mesmo estudo, a taxa de crescimento do colo da planta submetida ao ambiente com 50\% de luminosidade apresentou aumento significativo a partir de 82 dias, havendo tendência de maior desenvolvimento das plantas submetidas a $50 \%$ de luminosidade após os 145 dias em relação àquelas desenvolvidas a pleno sol. No entanto, em estudo realizado por Conceição e Dias-Filho (2013), os sombreamentos de 50\% e $75 \%$ proporcionaram maiores diâmetros que o sombreamento de $25 \%$. Tanto para o DC quanto para ALT, diferenças entre resultados obtidos nos diferentes estudos podem estar associados, dentre outros fatores, à variação em outras variáveis climáticas, além do sombreamento, tais como temperatura e umidade relativa do ar, bem como a diferentes substratos utilizados.

Foi observada resposta linear crescente e significativa do DC ao longo das épocas de avaliação para todos os substratos (Figura C). Em todas as épocas de avaliação, o S1, seguido do S2, foram os substratos que proporcionaram, estatisticamente, as maiores médias.

Segundo alguns autores (DALE, 1988; GORDON, 1989; JONES; MCLEOD, 1990), a área foliar das espécies tolerantes ao sombreamento tende a crescer com o aumento deste fator, pois expande a superfície fotossintética, assegurando aproveitamento mais eficiente das baixas intensidades luminosas, 
enquanto a área foliar das espécies que evitam o sombreamento aumenta em ambientes com maior disponibilidade de luz. No caso do taxi-branco, a AF das mudas cultivadas no sombreamento de $50 \%$ foi superior à obtida pelas mudas do sombreamento de $75 \%$, quando considerados os substratos S1 e S2 (Tabela 1), enquanto nas cultivadas com os substratos $\mathrm{S} 3$ e S4, não foram observadas diferenças significativas entre os níveis de sombreamento. Estes resultados mostram a habilidade do taxi-branco em utilizar a radiação fotossinteticamente ativa e alocar os fotoassimilados em resposta ao ambiente de maior luminosidade, no caso dos substratos $\mathrm{S} 1$ e $\mathrm{S} 2$.

Tabela 1- Médias do diâmetro do coleto (DC), índice de clorofila total (Chl $\mathrm{Ctotal}_{\text {al }}$, área foliar (AF), massa seca da raiz (MSR), da massa seca da parte aérea (MSPA), massa seca total (MST), razão parte aérea/raiz (PA/R) e índice de qualidade de Dickson (IQD), avaliadas em mudas de taxi-branco cultivadas em quatro

tipos de substrato (solo (S1); solo + areia (proporção volumétrica de 1:1; S2); solo + areia + serragem (proporção volumétrica de 2:1:1; S3); e solo + vermiculita (proporção volumétrica de 1:1; S4)) e dois níveis de sombreamento ( 50 e $75 \%$ ).

Table 1 - Mean values of stem diameter (DC), total chlorophyll index $\left(\mathrm{Chl}_{\text {total }}\right.$ ), leaf area (AF), dry mass of the root (MSR), dry mass of the shoot (MSPA), MSPA/MSR ratio (PA/R) and Dickson quality index (IQD) evaluated on taxi-branco seedlings cultivated in four types of substrate (soil - S1, soil + sand in the volumetric proportion of 1:1 - S2, soil + sand + sawdust in the proportion of 2:1:1 - S3 and soil + vermiculite in a ratio of 1:1 - S4) and two levels of shading $(50 \%$ and $75 \%)$.

\begin{tabular}{|c|c|c|c|c|c|c|c|c|c|c|c|c|c|c|c|c|}
\hline \multirow{3}{*}{$\begin{array}{c}\text { Substrato } \\
\text { S1 }\end{array}$} & \multicolumn{4}{|c|}{ DC (mm) } & \multicolumn{4}{|c|}{$\mathrm{Chl}_{\text {total }}$} & \multicolumn{4}{|c|}{$\mathrm{AF}\left(\mathbf{c m}^{2}\right)$} & \multicolumn{4}{|c|}{$\operatorname{MSR}(\mathrm{g})$} \\
\hline & \multicolumn{2}{|c|}{$50 \%$} & \multicolumn{2}{|c|}{$75 \%$} & \multicolumn{2}{|c|}{$50 \%$} & \multicolumn{2}{|c|}{$75 \%$} & \multicolumn{2}{|c|}{$50 \%$} & \multicolumn{2}{|c|}{$75 \%$} & \multicolumn{2}{|c|}{$50 \%$} & \multicolumn{2}{|c|}{$75 \%$} \\
\hline & 3,09 & $\mathrm{aA}$ & 2,35 & $\mathrm{aB}$ & 34,38 & $\mathrm{aA}$ & 31,9 & $\mathrm{aB}$ & 397,34 & $\mathrm{aA}$ & 260,2 & $\mathrm{aB}$ & $\begin{array}{c}1,59 \\
(1,53)\end{array}$ & $\mathrm{aA}$ & $\begin{array}{c}1,22 \\
(0,49)\end{array}$ & $\mathrm{aB}$ \\
\hline $\mathrm{S} 2$ & 2,91 & $\mathrm{aA}$ & 2,18 & $\mathrm{aA}$ & 31,11 & $\mathrm{bA}$ & 31,33 & $\mathrm{aA}$ & 328,18 & $\mathrm{bA}$ & 220,9 & $\mathrm{aB}$ & $\begin{array}{c}1,60 \\
(1,56)\end{array}$ & $\mathrm{aA}$ & $\begin{array}{c}1,23 \\
(0,51)\end{array}$ & $\mathrm{aB}$ \\
\hline S3 & 1,7 & $\mathrm{cA}$ & 1,33 & $\mathrm{bB}$ & 29,36 & $\mathrm{bB}$ & 34,28 & $\mathrm{aA}$ & 97,8 & $\mathrm{dA}$ & 83,34 & $\mathrm{bA}$ & $\begin{array}{c}1,10 \\
(0,21)\end{array}$ & $\mathrm{cA}$ & $\begin{array}{c}1,03 \\
(0,06)\end{array}$ & $\mathrm{bA}$ \\
\hline $\mathrm{S} 4$ & 2,55 & $\mathrm{bA}$ & 2,12 & $\mathrm{aB}$ & 30,74 & $\mathrm{bB}$ & 33,53 & $\mathrm{aA}$ & 233,19 & $\mathrm{cA}$ & 236,81 & $\mathrm{aA}$ & $\begin{array}{c}1,34 \\
(0,80)\end{array}$ & $\mathrm{bA}$ & $\begin{array}{c}1,19 \\
(0,42)\end{array}$ & $\mathrm{aB}$ \\
\hline Média & 2,56 & & 2 & & 31,4 & & 32,76 & & 264,13 & & 200,31 & & $\begin{array}{c}1,41 \\
(0,99)\end{array}$ & & $\begin{array}{c}1,17 \\
(0,37)\end{array}$ & $\begin{array}{c}1,17 \\
(0,37)\end{array}$ \\
\hline \multirow{2}{*}{ Substrato } & \multicolumn{4}{|c|}{$\operatorname{MSPA}(\mathrm{g})$} & \multicolumn{4}{|c|}{ MST (g) } & \multicolumn{4}{|c|}{$\mathbf{P A} / \mathbf{R}$} & \multicolumn{4}{|c|}{ IQD } \\
\hline & \multicolumn{2}{|c|}{$50 \%$} & \multicolumn{2}{|c|}{$75 \%$} & \multicolumn{2}{|c|}{$50 \%$} & \multicolumn{2}{|c|}{$75 \%$} & \multicolumn{2}{|c|}{$50 \%$} & \multicolumn{2}{|c|}{$75 \%$} & \multicolumn{2}{|c|}{$50 \%$} & \multicolumn{2}{|c|}{$75 \%$} \\
\hline S1 & 3,19 & $\mathrm{aA}$ & 1,56 & $\mathrm{aB}$ & 4,74 & $\mathrm{aA}$ & 2,06 & $\mathrm{aB}$ & 2,14 & $\mathrm{bA}$ & 3,3 & $\mathrm{bA}$ & $\begin{array}{c}1,29 \\
(0,66)\end{array}$ & $\mathrm{aA}$ & $\begin{array}{c}1,08 \\
(0,17)\end{array}$ & $\mathrm{aB}$ \\
\hline $\mathrm{S} 2$ & 2,54 & $\mathrm{bA}$ & 1,32 & $\mathrm{aB}$ & 4,12 & $\mathrm{aA}$ & 1,84 & $\mathrm{aB}$ & 1,78 & $\mathrm{bA}$ & 2,67 & $\mathrm{bA}$ & $\begin{array}{c}1,29 \\
(0,66)\end{array}$ & $\mathrm{aA}$ & $\begin{array}{c}1,08 \\
(0,17)\end{array}$ & $\mathrm{aB}$ \\
\hline S3 & 0,74 & $\mathrm{dA}$ & 0,44 & $\mathrm{bA}$ & 0,96 & $\mathrm{cA}$ & 0,48 & $\mathrm{bA}$ & 4,14 & $\mathrm{aB}$ & 8,8 & $\mathrm{aA}$ & $\begin{array}{c}1,06 \\
(0,12)\end{array}$ & $\mathrm{cA}$ & $\begin{array}{c}1,01 \\
(0,02)\end{array}$ & $\mathrm{bB}$ \\
\hline $\mathrm{S} 4$ & 1,71 & $\mathrm{cA}$ & 1,36 & $\mathrm{aB}$ & 2,5 & $\mathrm{bA}$ & 1,78 & $\mathrm{aB}$ & 2,26 & $\mathrm{bA}$ & 3,4 & $\mathrm{bA}$ & $\begin{array}{c}1,18 \\
(0,39)\end{array}$ & $\mathrm{bA}$ & $\begin{array}{c}1,07 \\
(0,14)\end{array}$ & $\mathrm{aB}$ \\
\hline Média & 2,05 & 2,05 & 1,17 & 1,17 & 3,08 & 3,08 & 1,54 & 1,54 & 2,59 & 2,59 & 4,61 & 4,61 & $\begin{array}{c}1,21 \\
(0,46)\end{array}$ & $\begin{array}{c}1,21 \\
(0,46)\end{array}$ & $\begin{array}{c}1,06 \\
(0,13)\end{array}$ & \\
\hline
\end{tabular}

Médias seguidas de mesma letra minúscula na coluna e maiúscula na linha não diferem entre si pelo teste de Tukey, a 5\% de probabilidade. Médias entre parênteses indicam médias dos valores não transformados.

Resultados diferentes em relação à AF foram encontrados por Pacheco et al. (2013) com jacarandá-da-bahia (Dalbergia nigra (Vell.) Allemão ex. Benth), por Rego e Possamai (2006) com jequitibá-rosa (Cariniana legalis Mart.) e por Silva et al. (2007) com jutaí-mirim (Hymenaea parvifolia Huber.). Entretanto, corroborando os resultados obtidos no presente estudo, mudas de pau-ferro (Caesalpinia ferrea Mart. ex. Tul. var. leiostachya) também apresentaram maior AF quando submeti- 
das ao nível de 50\% de luminosidade (LENHARD et al., 2013).

Sob elevada irradiância, a taxa de degradação de clorofila é maior do que a de síntese (GONÇALVES et al., 2012), sendo assim, o teor de clorofila tende a aumentar com a redução da intensidade luminosa. Segundo Martinazzo et al. (2007), o maior acúmulo de clorofila em ambientes mais sombreados pode ser devido ao efeito compensatório da espécie à menor quantidade de radiação disponível. Este fato pode ser observado no presente estudo, em que o maior nível de sombreamento (75\%) proporcionou maiores índices de $\mathrm{Chl}_{\text {total }}$ para a maioria dos substratos, com exceção para o S1 (Tabela 1). Almeida et al. (2005) também observaram maior acúmulo de clorofila no nível de maior sombreamento para quatro espécies florestais (Maclura tinctoria, Senna macranthera, Hymenaea courbaril e Acacia mangium). Não foram observadas diferenças significativas entre os substratos no nível de $75 \%$ de sombreamento.

Exceto para o S3, as variáveis MSR, MSPA e MST (Tabela 1) apresentaram maiores médias no sombreamento de $50 \%$, o que pode ter sido ocasionado pelo aumento da fotossíntese sob maior disponibilidade de luz, aumentando, consequentemente, o teor de nutrientes nas folhas, caule e raízes. Esses resultados corroboram os observados por Felfili et al. (1999) ao analisarem mudas de taxi-branco. No entanto, em estudo realizado por Conceição e Dias-Filho (2013), mudas da espécie apresentaram maior produção de matéria seca sob maiores níveis de sombreamento (75\%). Freitas et al. (2012) obtiveram maiores valores de massa seca das folhas, do caule, da raiz e massa seca total para mudas submetidas a ambientes de pleno sol. Neste estudo, ao serem comparadas apenas as condições de $50 \%$ de sombreamento e de sombra natural, maior crescimento foi obtido no sombreamento de $50 \%$. No sombreamento de $50 \%$, os substratos S1 e S2 geralmente se destacaram em relação aos demais.

Segundo Almeida et al. (2005), maior biomassa radicular propicia melhor desempenho das mudas no campo, especialmente em áreas degradadas, pois a probabilidade de sobrevivência da planta será maior, em razão da maior facilidade de sustentação e maior área para absorção de água e nutrientes.

Com exceção do substrato $\mathrm{S} 3$, cuja razão parte aérea/raiz (PA/R) foi maior na condição de $75 \%$ de sombreamento, não foram observadas diferenças significativas quanto a esta variável entre os dois níveis de sombreamento para os demais substratos. Conceição e Dias-Filho (2013) também não observaram diferenças significativas para essa variável em mudas de taxi-branco cultivadas sob diferentes níveis de sombreamento. Felfili et al. (1999) e Freitas et al. (2012), por outro lado, mostraram que houve uma tendência para um aumento de investimento na produção de biomassa da parte aérea, em detrimento do sistema radicular, em mudas de taxi-branco, à proporção que a luz se tornou menos disponível.

Os menores valores de PA/R obtidos nos substratos S1, S2 e S4 permitem inferir que estes substratos promovem uma distribuição equilibrada de fotoassimilados na planta, o que pode ter ocorrido devido às melhores condições físicas, químicas e/ou hídricas desses substratos. Estes menores valores de PA/R, associados aos maiores valores de MSPA, MSR e MST observados para os substratos $\mathrm{S} 1$ e S2, indicam que estes dois substratos são capazes de proporcionar mudas de melhor qualidade e, portanto, de maior desempenho no campo.

O IQD é considerado uma boa variável para avaliar a qualidade de mudas, uma vez que leva em consideração o equilíbrio da distribuição da biomassa da muda, ponderando os resultados de várias variáveis (FONSECA et al., 2002). O sombreamento de $50 \%$ foi o que proporcionou mudas com maiores valores de IQD em todos os substratos, com destaque para os substratos S1 e S2 (Tabela 1). O sombreamento de $75 \%$ proporcionou valores de IQD menores que 0,20 , que é o valor mínimo recomendado para que uma muda seja considerada de boa qualidade (HUNT, 1990), para todos os substratos.

Conceição e Dias-Filho (2013) mostraram que o tratamento de $50 \%$ de sombra foi o que apresentou maior valor $(2,69)$ para o IQD, em mudas de taxi-branco, embora bem próximo ao valor obtido $(2,60)$ para o sombreamento de $75 \%$. Em estudo realizado por Freitas et al. (2012), à medida que houve diminuição do nível de sombreamento, mudas de taxi-branco apresentaram maior IQD. Os valores de IQD obtidos por aqueles primeiros autores foram superiores aos obtidos no presente estudo, enquanto aqueles obtidos por Freitas et al. (2012) foram similares. 


\section{Análises microbiológicas}

O taxi-branco é uma leguminosa arbórea que pode apresentar associação com bactérias fixadoras de $\mathrm{N}$ atmosférico. $\mathrm{O}$ número de nódulos presente em uma planta está relacionado com a densidade de bactérias estabelecidas no substrato e representa uma medida semiquantitativa do número de células presentes nos mesmos (NÓBREGA et al., 2008). Os substratos que continham apenas solo e os que continham serragem ou vermiculita em sua composição ( $\mathrm{S} 1, \mathrm{~S} 3$ e S4, respectivamente) foram os que produziram as menores médias de NN (18, 14 e 12 nódulos, respectivamente), não diferindo significativamente entre si (Tabela 2). Por outro lado, o substrato S2, ou seja, aquele que continha solo + areia, foi o que apresentou o maior NN, com média de 37 nódulos.

\section{Tabela 2 - Médias do número de nódulos (NN) obtidos em mudas de taxi-branco, cultivadas em quatro tipos de substrato (solo (S1); solo + areia (proporção volumétrica de 1:1; S2); solo + areia + serragem (proporção volumétrica de 2:1:1; S3); e solo + vermiculita (proporção volumétrica de 1:1; S4)).}

Table 2 - Mean number of nodules obtained in taxi-branco seedlings, grown on four substrate types of substrate (soil - S1, soil + sand in the volumetric proportion of 1:1 - S2, soil + sand + sawdust in the proportion of 2:1:1 - S3 and soil + vermiculite in a ratio of 1:1 - S4).

\begin{tabular}{clc}
\hline Substrato & \multicolumn{2}{c}{ Número de nódulos } \\
\hline S1 & $4,33(18)$ & B \\
S2 & $6,19(37)$ & A \\
S3 & $3,91(14)$ & B \\
S4 & $3,56(12)$ & B \\
\hline
\end{tabular}

Médias seguidas de mesma letra não diferem entre si pelo teste de Tukey, a $5 \%$ de probabilidade. Médias entre parênteses indicam médias dos valores não transformados.

Segundo Nóbrega et al. (2008), solos de textura mais arenosa proporcionaram um meio mais poroso, favorecendo maior aeração e infiltração de água no tubete e, consequentemente, melhor nodulação de mudas de sesbânia [Sesbania virgata (Caz.) Pers]. Este fato pode explicar o maior NN observado para o S2, uma vez que metade da composição deste substrato foi constituído por areia.

As mudas desenvolvidas sob menor sombreamento (50\%) e com os substratos $\mathrm{S} 1$ e S2, além de ter apresentado maiores valores para a maioria das variáveis morfológicas avaliadas, apresentaram, também, maior qualidade, avaliada pelo IQD. No entanto, comparando-se os melhores substratos, o S2 apresenta maior praticidade de uso, uma vez que o S1 tendeu a apresentar maior compactação quando avaliado visualmente, necessitando, desta forma, de maior controle da irrigação, principalmente se o período de produção da muda coincide com o período mais seco do ano.

A observação de que o substrato $\mathrm{S} 3$ foi o que proporcionou mudas com as menores médias para a maioria das variáveis avaliadas, concorda com Gondin et al. (2015), que, em pesquisa com o paricá (Schizolobium amazonicum Huber ex Ducke), observaram que o desenvolvimento do sistema radicular dessa espécie foi prejudicado quando as mudas foram cultivadas com substratos que possuíam pó de serra fresco ou curtido em sua composição. De acordo com Burés (1997), dependendo do tempo de armazenamento, a serragem pode ser usada como substrato sem a necessidade de realizar compostagem. Entretanto, mesmo nas serragens envelhecidas e naturalmente compostadas, podem ocorrer processos anaeróbios de fermentação, gerando ácidos orgânicos que interferem no crescimento de raízes, sendo esse um dos principais fatores limitantes ao uso desse subproduto como substrato.

Do total de mudas sobreviventes avaliadas (156), apenas quatro não apresentaram nodulação. No total foram obtidos 159 isolados bacterianos de 304 nódulos avaliados. O sombreamento, o substrato e a interação entre estes dois fatores não foram significativos $(\mathrm{P}>0,05)$ para o NI (dados não apresentados).

Do total de isolados bacterianos caracterizados, $83,65 \%$ apresentaram crescimento muito rápido, 
sendo os demais caracterizados como de crescimento rápido (Tabela 3). A maioria dos isolados acidificou o meio de cultura $(76,73 \%)$ e apresentou colônias de forma circular $(86,16 \%)$, borda e superfície lisa (96,23\% e 98,74\%, respectivamente), diâmetro inicial de até $1,9 \mathrm{~mm}(71,70 \%)$ e diâmetro final de $8 \mathrm{~mm}$ ou mais (50,31\%). Em relação ao muco, 37,74\% apresentou produção abundante e 33,33\% produção moderada. $71,70 \%$ dos isolados apresentaram muco com consistência aquosa, 65,41\% transparente, 81,13\% de aparência heterogênea, $61,01 \%$ sem elasticidade e $44,65 \%$ e $41,51 \%$ de coloração bege ou incolor, respectivamente.

Tabela 3 - Caracterização fenotípica de 159 isolados obtidos de 304 nódulos bacterianos coletados de mudas de taxi-branco, cultivadas em dois níveis de sombreamento, quatro tipos de substrato e avaliadas aos seis meses após o transplantio.

Table 3 - Phenotypic characterization of 159 isolates obtained from 304 bacterial nodules, collected from taxi-branco seedlings, grown at two levels of shading, four types of substrate and evaluated six months after transplanting.

\begin{tabular}{|c|c|c|}
\hline Variáveis avaliadas & Característica & Número de isolados \\
\hline \multirow{3}{*}{$\begin{array}{l}\text { Tempo de crescimento } \\
\text { (horas) }\end{array}$} & Muito rápido & 133 \\
\hline & Rápido & 26 \\
\hline & Puntiforme & 2 \\
\hline \multirow[t]{3}{*}{ Forma da Colônia } & Circular & 137 \\
\hline & Irregular & 20 \\
\hline & Plana & 94 \\
\hline \multirow[t]{2}{*}{ Elevação da Colônia } & Lenticular & 63 \\
\hline & Convexa & 2 \\
\hline \multirow{2}{*}{ Borda da Colônia } & Lisa & 153 \\
\hline & Ondulada & 6 \\
\hline \multirow{3}{*}{ Superfície da Colônia } & Lisa & 157 \\
\hline & Rugosa & 2 \\
\hline & Escassa & 10 \\
\hline \multirow{4}{*}{ Produção de Muco } & Pouca & 36 \\
\hline & Moderada & 53 \\
\hline & Abundante & 60 \\
\hline & Opaca & 11 \\
\hline \multirow[t]{3}{*}{ Transparência do Muco } & Transparente & 104 \\
\hline & Translúcida & 44 \\
\hline & Aquosa & 114 \\
\hline \multirow{3}{*}{ Consistência do Muco } & Seca & 7 \\
\hline & Butírica & 2 \\
\hline & Gomosa & 36 \\
\hline
\end{tabular}

Continua... 
Tabela 3 - Conclusão...

Table 3 - Conclusion...

\begin{tabular}{|c|c|c|}
\hline Variáveis avaliadas & Característica & Número de isolados \\
\hline \multirow{5}{*}{ Cor do Muco } & Branco & 8 \\
\hline & Incolor & 66 \\
\hline & Bege & 71 \\
\hline & Amarelo & 15 \\
\hline & Homogêneo & 30 \\
\hline Aparência do Muco & Heterogêneo & 129 \\
\hline \multirow{2}{*}{ Elasticidade do Muco } & Sim & 62 \\
\hline & Não & 97 \\
\hline \multirow{4}{*}{ Diâmetro inicial (mm) } & Até $1 \mathrm{~mm}$ & 114 \\
\hline & 2 a $3 \mathrm{~mm}$ & 35 \\
\hline & 4 a $5 \mathrm{~mm}$ & 9 \\
\hline & 6 a $7 \mathrm{~mm}$ & 1 \\
\hline \multirow{5}{*}{ Diâmetro final (mm) } & Até $1 \mathrm{~mm}$ & 4 \\
\hline & 2 a $3 \mathrm{~mm}$ & 18 \\
\hline & 4 a $5 \mathrm{~mm}$ & 32 \\
\hline & 6 a $7 \mathrm{~mm}$ & 25 \\
\hline & $8 \mathrm{~mm}$ ou mais & 80 \\
\hline \multirow{3}{*}{ pH do meio } & Ácido & 122 \\
\hline & Neutro & 26 \\
\hline & Alcalino & 11 \\
\hline
\end{tabular}

Através do dendrograma de similaridade é possível observar a formação de 37 grupos (Figura 2), ao se considerar um nível de similaridade de $70 \%$. O maior grupo observado foi o 24 , o qual apresentou 49 isolados, dos quais 12 foram oriundos do substrato S1, 18 do substrato S2, 10 do S3 e 9 do S4. Este grupo se destacou dos demais por apresentar maior distribuição entre os tipos de substratos e maior heterogeneidade. Em relação ao nível de sombreamento, os isolados se dividiram dentre os dois níveis. Os isolados do grupo compartilham características de crescimento muito rápido, $\mathrm{pH}$ do meio ácido, forma da colônia circular a irregular, elevação da colônia plana a lenticular, borda lisa, superfície lisa a rugosa, produção de muco moderado a abundante, muco transparente, com consistência aquosa e aparência heterogênea.

O segundo maior grupo formado foi o 28 , com 14 isolados, sendo que, destes, três foram do tratamento S1, dois do S2, cinco do S3 e quatro do S4. Em relação ao sombreamento, houve predominância de isolados do nível de 75\% (aproximadamente 71\%). Os menores grupos foram G4, G6, G11, G21, G22, G25, G32, G34, G35 e G37, os quais apresentaram apenas 1 isolado cada um. Dentre esses, 6 grupos tiveram isolados do substrato $\mathrm{S} 4$.

O S4 foi o que apresentou maior riqueza de espécies de rizóbios, uma vez que os isolados obtidos deste substrato se distribuíram em 23 grupos, ou seja, em $62 \%$ dos grupos formados. Por outro lado, a menor diversidade foi observada no $\mathrm{S} 2$, com isolados distribuídos em 13 grupos.

Atualmente há uma estirpe de rizóbio recomendada para a produção de mudas de $T$. vulgaris (FRANCO; FARIA, 1997; BRASIL, 2011), porém, não há trabalhos publicados sobre isolamento e caracterização de rizóbios em simbiose com esta leguminosa e, entre os isolados obtidos, poderão existir rizóbios mais eficientes para a fixação biológica de nitrogênio. 
Figura 2 - Dendrograma de similaridade dos isolados oriundos de mudas de taxi-branco. Porcentagem de $25 \%$ e $50 \%$ representam os sombreamentos de $75 \%$ e $50 \%$, respectivamente, a letra $\mathrm{B}$ representa o bloco, $\mathrm{T}$ o tipo de substrato, $\mathrm{P}$ o número da planta e $\mathrm{N}$ o nódulo.

Figure 2 - Similarity dendrogram of isolates from taxi-branco seedlings. Percentage of $25 \%$ and $50 \%$ represent shading of $75 \%$ and $50 \%$, respectively, the letter B the block, T the type of substrate and $\mathrm{N}$ the nodule.

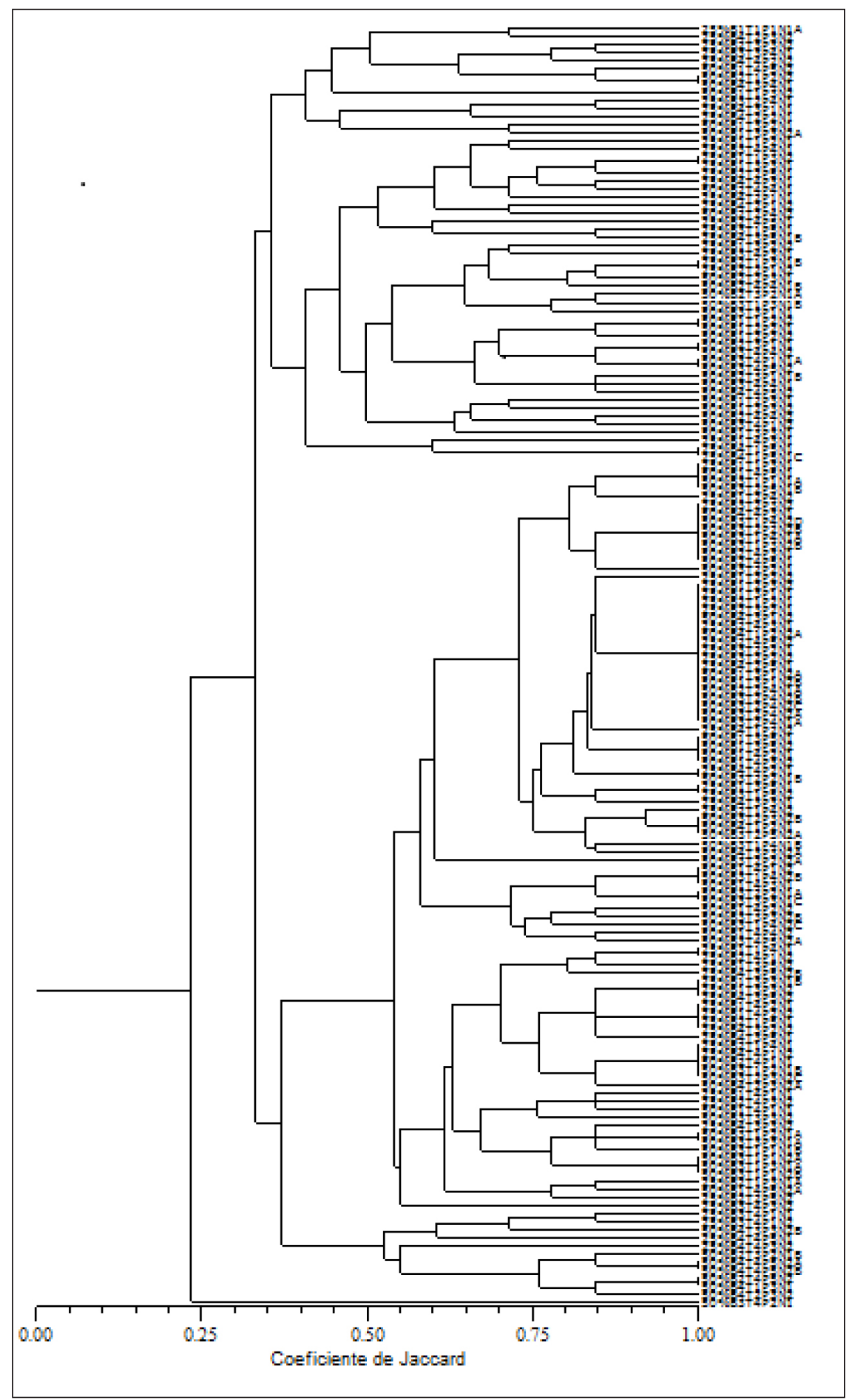




\section{Conclusão}

Para a produção de mudas de taxi-branco em Roraima, é indicado o sombreamento de $50 \%$ e o substrato composto por mistura de solo + areia, na proporção volumétrica de 1:1. Apesar de o número de isolados não ter sido influenciado pelos níveis de sombreamento e tipos de substratos avaliados, a espécie demonstrou capacidade de realização associativa com grande diversidade de rizóbios, sendo que, em sua maioria, os isolados apresentaram tempo de crescimento muito rápido e $\mathrm{pH}$ ácido do meio de cultura.

\section{Referências}

AGUIAR, F. F. A. et al. Crescimento de mudas de pau-brasil (Caesalpinia echinata Lam.), submetidas a cinco níveis de sombreamento. Revista Ceres, Viçosa, MG, v. 58, n. 6, p. 729-734, nov./dez. 2011.

ALMEIDA, S. M. Z. et al. Alterações morfológicas e alocação de biomassa em plantas jovens de espécies florestais sob diferentes condições de sombreamento. Ciência Rural, Santa Maria, v. 35, n. 1, p. $62-68$, jan./fev. 2005.

BRASIL. Ministério da Agricultura, Pecuária e Abastecimento. Instrução normativa $n^{\circ}$ 13, de 24 de março de 2011. Diário Oficial da União da República Federativa do Brasil, Brasília, 25 mar. 2011. Seção 1.

BURÉS, S. Substratos. Madri: Agrotécnicas, 1997.

CALDEIRA, M. V. W. et al. Efeito de fungos micorrízicos arbusculares no desenvolvimento de duas leguminosas arbóreas. Ciência Florestal, Santa Maria, v. 9, n. 1, p. 63-70, 1999.

CARVALHO FILHO, J. L. S. et al. Produção de mudas de jatobá (Hymenaea courbaril L.) em diferentes ambientes, recipientes e composições de substratos. Cerne, Lavras, v. 9, n. 1, p. 109-118, 2003.

CONCEIÇÃO, A. C.; DIAS-FILHO, M. B. Níveis de sombreamento para produção de mudas de taxi-branco (Sclerolobium paniculatum Vogel). Revista do Instituto Florestal, São Paulo, v. 25, n. 2, p. 151-161, dez. 2013.

CUNHA, A. O. et al. Efeito de substratos e das dimensões dos recipientes na qualidade das mudas de Tabebuia impetiginosa (Mart. Ex D.C.) Standl. Revista Árvore, Viçosa, MG, v. 29 , n. 4 , p. 507-516, jul./ago. 2005.

DALE, J. E. The control of leaf expansion. Annual Review of Plant Physiology and Plant Molecular Biology, Palo Alto, v. 39, p. 267-295, jun. 1988.

DANTAS, B. F. et al. Taxas de crescimento de mudas de catingueira submetidas a diferentes substratos e sombreamentos. Revista Árvore, Viçosa, MG, v. 33, n. 3, p. 413-423, 2009.

DIAS, L. E. et al. Formação de mudas de táxi-branco (Sclerolobium paniculatum Vogel): resposta a nitrogênio, potássio e enxofre. Revista Árvore, Viçosa, MG, v. 16, n. 2, p. 135-143, 1992.

DUTRA, T. R. Crescimento e nutrição de mudas de copaíba em dois volumes de substratos e níveis de sombreamento. 2010. 54 f. Dissertação (Mestrado em Produção Vegetal) - Universidade Federal dos Vales do Jequitinhonha e Mucuri, Diamantina, 2010.

DUTRA, T. R.; MASSAD, M. D.; SANTANA, R. C. Parâmetros fisiológicos de mudas de copaíba sob diferentes substratos e condições de sombreamento. Ciência Rural, Santa Maria, v. 42, n. 7, p. 1212-1218, jul. 2012.

FELFILI, J. M. et al. Comportamento de plântulas de Sclerolobium paniculatum Vog. Var. rubiginosum (Tul.) Benth. sob diferentes níveis de sombreamento em viveiro. Revista Brasileira de Botânica, São Paulo, v. 22, n. 2, p. 297-301, out. 1999.

FERREIRA, D. F. Sisvar: a computer statistical analysis system. Ciência e Agrotecnologia, Lavras, v. 35, n. 6, p. 1039-1042, nov./dez. 2011. 
FONSECA, E. P. et al. Padrão de qualidade de mudas de Trema micrantha (L.) Blume, produzidas sob diferentes períodos de sombreamento. Revista Árvore, Viçosa, MG, v. 26, n. 4, p. 515-523, 2002.

FRANCO, A. A.; FARIA, S. M. The contribution of N2 fixing tree legumes to land reclamation and sustainability in the tropics. Soil Biology and Biochemistry, Amsterdam, v. 29, p. 897-903, maio/jun. 1997.

FRED, E. B.; WAKSMAN, S. A. Laboratory manual of general microbiology. New York: McGrawHill Book, 1928.

FREITAS, G. A. et al. Influência do sombreamento na qualidade de mudas de Sclerolobium paniculatum Vogel para recuperação de área degradada. Journal of Biotechnology and Biodiversity, [S.1.], v. 3, n. 3, p. 5-12, ago. 2012.

GOMES, J. M. Parâmetros morfológicos na avaliação da qualidade de mudas de Eucalyptus grandis, produzidas em diferentes tamanhos de tubete e de dosagens de NPK. 2001. 166 f. Tese (Doutorado em Ciências Florestais) - Universidade Federal de Viçosa, Viçosa, MG, 2001.

GONÇALVES, J. F. C. et al. Efeito do ambiente de luz no crescimento de plantas jovens de mogno (Swietenia macrophylla King). Scientia Forestalis, v. 40, n. 95, p. 337-344, set. 2012.

GONDIN, J. C. et al. Emergência de plântulas de Schizolobium amazonicum Huber ex Ducke (Caesalpinaceae) em diferentes substratos e sombreamento. Revista Ciência Agronômica, Fortaleza, v. 46, n. 2, p. 329-338, abr./jun. 2015.

GORDON, J. C. Effect of shade on photosynthesis and dry weight distribution in yellow birch (Betula alleghaniensis Britton) seedlings. Ecology, [S.1.], v. 50, n. 5, p. 924-926, set. 1989.

HUNT, G. A. Effect of styroblock design and Cooper treatment on morphology of conifer seedlings. In: PROCEEDINGS TARGET SEEDLING SYMPOSIUM; MEETING OF THE WESTERN FOREST NURSERY ASSOCIATION, 1990, Fort Collins. Anais... Fort Collins: United States Departament of Agriculture, Forest Service, 1990. p. 218-222.

JONES, R. H.; MCLEOD, K. W. Responses to a range of light environments in Chinese Tallowtree and Carolina Ash seedlings. Forest Science, Oxford, v. 36, p. 851-862, dez. 1990.

LENHARD, N. R. et al. Crescimento de mudas de pau-ferro sob diferentes níveis de sombreamento. Pesquisa Agropecuária Tropical, Goiânia, v. 43, n. 2, p. 178-186, abr./jun. 2013.

LIMA, R. M. B. Crescimento do Sclerolobium paniculatum Vogel na Amazônia, em função de fatores de clima e solo. 2004. 194 f. Tese (Doutorado em Ciências Agrárias) - Universidade Federal do Paraná, Curitiba, 2004.

LORENZI, H. Árvores brasileiras: manual de identificação e cultivo de plantas arbóreas nativas do Brasil. 2. ed. [S.1.]: Instituto Plantarum de Estudos da Flora, 2002. v. 2.

MARINHO, N. F. et al. Respostas de Acacia mangium Willd e Sclerolobium paniculatum Vogel a fungos micorrízicos arbusculares nativos provenientes de áreas degradadas pela mineração de bauxita na Amazônia. Acta Botanica Brasileira, São Paulo, v. 18, n. 1, p. 141-149, mar. 2004.

MARTINAZZO, E. G. et al. Efeito do sombreamento sobre o crescimento inicial e teor de clorofila foliar de Eugenia uniflora Linn (Pitanga) - Família Mirtaceae. Revista Brasileira de Biociências, Porto Alegre, v. 5, n. 2, p. 162-164, jul. 2007.

MORAES NETO, S. P. et al. Crescimento de mudas de algumas espécies arbóreas que ocorrem na mata atlântica em função do nível de luminosidade. Revista Árvore, Viçosa, MG, v. 24, n. 1, p. 35-45, 2000.

NÓBREGA, R. S. A. et al. Parâmetros morfológicos de mudas de Sesbania virgata (Caz.) Pers e de Anadenanthera peregrina (L.) cultivadas em substrato fertilizado com composto de lixo urbano. Revista Árvore, Viçosa, MG, v. 32, n. 3, p. 597-607, 2008.

PACHECO, F. V. et al. Crescimento inicial de Dalbergia nigra (Vell.) Allemão ex. Benth. (Fabaceae) e Chorisia speciosa A.St.-Hil (Malvaceae) sob diferentes níveis de sombreamento. Revista Árvore, Viçosa, MG, v. 37, n. 5, p. 945-953, 2013.

Ci. Fl., Santa Maria, v. 29, n. 1, p. 116-129, jan./mar., 2019 
REGO, G. M.; POSSAMAI, E. Efeito do sombreamento sobre o teor de clorofila e crescimento inicial do jequitibá-rosa. Pesquisa Florestal Brasileira, Colombo, n. 53, p. 179-194, 2006.

SCALON, S. P. Q. et al. Germinação e crescimento de mudas de pitangueira sob condições de sombreamento. Revista Brasileira de Fruticultura, Jaboticabal, v. 23, n. 3, p. 652-655, dez. 2001.

SIEBENEICHLER, S. C. et al. Características morfofisiológicas em plantas de Tabebuia heptaphylla (Vell.) Tol. em condições de luminosidade. Acta Amazônica, Manaus, v. 38, n. 3, p. 467-472, 2008.

SILVA, B. M. S. et al. Efeito da luz no crescimento de mudas de Hymenaea parvifolia Huber. Revista Árvore, Viçosa, MG, v. 31, n. 6, p. 1019-1026, 2007.

SOUZA, C. R. et al. Taxi-branco (Sclerolobium paniculatum Vogel) Manaus. Manaus: EMBRAPA Amazônia Ocidental, 2004. (Documentos, 34).

VALE, A. T. et al. Quantificação e caracterização energética da madeira e casca de espécies do cerrado.

Ciência Florestal, Santa Maria, v. 12, n.1, p. 71-80, 2002. 